Article

\title{
Bioassay-Guided Different Extraction Techniques of Carica papaya (Linn.) Leaves on In Vitro Wound-Healing Activities
}

\author{
Husnul Hanani Soib ${ }^{1}$, Hassan Fahmi Ismail ${ }^{2}{ }^{-0}$, Fitrien Husin ${ }^{3}$, Mohamad Hafizi Abu Bakar ${ }^{4}(\mathbb{D}$, \\ Harisun Yaakob ${ }^{1,3, *}$ and Mohamad Roji Sarmidi ${ }^{5}$ \\ 1 Department of Bioprocess and Polymer Engineering, School of Chemical and Energy Engineering, Faculty of \\ Engineering, University Teknologi Malaysia, Skudai 81310, Malaysia; hannanmh88@gmail.com \\ 2 Institute of Marine Biotechnology, Universiti Malaysia Terengganu, Kuala Terengganu 21030, Malaysia; \\ h.fahmi@umt.edu.my \\ 3 Institute of Bioproduct Development, University Teknologi Malaysia, Skudai 81310, Malaysia; \\ fitrienh@gmail.com \\ 4 Bioprocess Technology Division, School of Industrial Technology, Universiti Sains Malaysia, Gelugor 11800, \\ Penang, Malaysia; mhafizi88@usm.my \\ 5 Innovation Centre in Agritechnology for Advanced Bioprocessing (ICA), University Teknologi Malaysia, \\ Skudai 81310, Malaysia; mroji@utm.my \\ * Correspondence: harisun@ibd.utm.my
}

Received: 21 November 2019; Accepted: 7 January 2020; Published: 24 January 2020

Abstract: Herbal plants are traditionally utilized to treat various illnesses. They contain phytochemicals that can be extracted using conventional methods such as maceration, soxhlet, and boiling, as well as non-conventional methods including ultrasonic, microwave, and others. Carica papaya leaves have been used for the treatment of dengue, fungal, and bacterial infections as well as an ingredient in anti-aging products. Phytochemicals analysis detected the presence of kaempferol, myricetin, carpaine, pseudocarpaine, dehydrocarpaine I and II, ferulic acid, caffeic acid, chlorogenic acid, $\beta$-carotene, lycopene, and anthraquinones glycoside. Conventional preparation by boiling and simple maceration is practical, simple, and safe; however, only polar phytochemicals are extracted. The present study aims to investigate the effects of three different non-conventional extraction techniques (ultrasonic-assisted extraction, reflux, and agitation) on C. papaya phytochemical constituents, the antioxidant capacity, and wound-healing activities. Among the three techniques, the reflux technique produced the highest extraction yield (17.86\%) with the presence of saponins, flavonoids, coumarins, alkaloids, and phenolic metabolites. The reflux technique also produced the highest 2, 2-diphenyl-1-picrylhydrazyl (DPPH) radical scavenging with an $\mathrm{IC}_{50}$ value of $0.236 \mathrm{mg} / \mathrm{mL}$ followed by ultrasonic-assisted extraction (UAE) $\left(\mathrm{IC}_{50}: 0.377 \mathrm{mg} / \mathrm{mL}\right.$ ) and agitation $\left(\mathrm{IC}_{50}: 0.404 \mathrm{mg} / \mathrm{mL}\right)$. At tested concentrations $(3.125 \mu \mathrm{g} / \mathrm{mL}$ to $500 \mu \mathrm{g} / \mathrm{mL})$, all extracts do not exhibit a cytotoxicity effect on the human skin fibroblast, HSF1184. Interestingly, reflux and UAE were active fibroblast proliferators that support $85 \%(12.5 \mu \mathrm{g} / \mathrm{mL})$ and $41 \%(6.25 \mu \mathrm{g} / \mathrm{mL})$ better cell growth, respectively. Additionally, during the early $24 \mathrm{~h}$ of the scratch assay, the migration rate at $12.5 \mu \mathrm{g} / \mathrm{mL}$ was faster for all extracts with $51.8 \%$ (reflux), $49.3 \%$ (agitation), and $42.5 \%$ (UAE) as compared to control $(21.87 \%)$. At $48 \mathrm{~h}$, proliferated cells covered $78.7 \%$ of the scratch area for reflux extract, $63.1 \%$ for UAE, $61 \%$ for agitation, and $42.6 \%$ for control. Additionally, the collagen synthesis was enhanced for $31.6 \%$ and $65 \%$ after 24 and $48 \mathrm{~h}$ of treatment for reflux. An HPLC-MS/MS-QTOF (quadruple time-of-flight) analysis of reflux identified nine phytochemicals, including carpaine, kaempferol 3-(2G-glucosylrutinoside), kaempferol 3-(2"-rhamnosylgalactoside), 7-rhamnoside, kaempferol 3-rhamnosyl-(1->2)-galactoside-7-rhamnoside, luteolin 7-galactosyl-(1->6)-galactoside, orientin 7-O-rhamnoside, 11-hydroperoxy-12,13-epoxy-9-octadecenoic acid, palmitic amide, and 2-hexaprenyl-6-methoxyphenol. The results suggested that reflux was the best technique as compared to ultrasonic and agitation. 
Keywords: Carica papaya; antioxidant; wound healing; extraction; conventional

\section{Introduction}

Skin is a major organ comprising $15 \%-20 \%$ of total body weight [1]. Microbial infection, ultraviolet light, chemical damages, and physical damages cause wounds that disrupt the structure and functionality of skin. Wound healing is a complex and dynamic process comprising multiple interactions among cellular structures, tissue layers, and different types of cells. It involves three major processes: inflammation, proliferation, and tissue remodeling. Upon skin injury, the body will undergo a homeostasis of vasoconstriction and platelet aggregation for blood clotting. Simultaneously, cells at the affected area secrete cytokines, water, salts, and proteins. Proliferation cascades are achieved by the migration of fibroblasts and keratinocytes along with the fibrin network, angiogenesis, and reepithelialization. During the final stage of tissue remodeling, type III collagen that is synthesized during the proliferation stage is remodeled into stronger type I collagen, which reduces scar size and increases the tensile strength.

Carica papaya Linn, also known as betik in Malaysia, belongs to the Caricaceae family. It is a soft-stemmed perennial plant that can grow up to $20 \mathrm{~m}$ without branches. It is the most cultivated plant in tropical and subtropical countries. In Malaysia, there are several varieties of C. papaya such as Eksotika, Sekaki, Subang, and Solo. However, among these varieties, Eksotika contained an abundance of metabolites, and it is the most popular variety in Malaysia. Studies revealed that the presence of compounds in the C. papaya exhibits various biological activities such as anti-diabetes [2], anti-fertility [3], anti-fungal [4,5], anti-bacterial [6,7], anti-tumor [8], antioxidant [9], anti-dengue [10], and anti-plasmodial [11], despite the different parts of the papaya plant. As described by Muhamad et al., 2017, Asghar et al., 2016, and Tay and Chong, 2016, the C. papaya plant contained an abundance of polar compounds rather than non-polar compounds [5,12,13]. Nugroho et al., 2017 reported seven flavonoid compounds from a butanol fraction of methanol extract of $C$. papaya leaves, including quercetin 3-( $2^{\mathrm{G}}$-rhamnosyrutinoside), kaempherol 3-(2 $2^{\mathrm{G}}$-rhamnosylrutinoside), quercetin 3-rutinoside, myricetin 3-rhamnoside, kaempherol 3-rutinoside, quercetin, and kaempherol, which have been tested for antioxidant activity by peroxynitrite scavenging assays [14]. The results showed that these flavonoids possessed potent antioxidant properties even when being compared to the positive control, which was L-penicillamine. Afzan et al., 2012 also has successfully detected malic acid, quinic acid, caffeoyl malate, quercetin-3-O-(2",6"-di-O-rhamnopyranosyl) glucopyranoside (manghaslin), p-coumaroyl malate, kaempherol-3-O-(2",6"-di-O-rhamnopyranosyl) glucopyranoside (clitorin), quercetin-3-O-rutinoside (rutin), kaempherol-3-O-rutinoside (nicotiflorin), and carpaine from leaves extract of $C$. papaya [15]. Furthermore, various studies on the effect of $C$. papaya on wound-healing activities have been previously reported [16-19]. The wound-healing properties were attributed by antioxidant, anti-inflammatory, and antimicrobial activities [20].

The demand for the natural product and plant-based phytochemicals has increased in trend by incorporating the herbs into modern medical practice. Realizing the impact of its use, a selective extraction technique has always been challenging. It is an important consideration to assure that the bioactive compounds that are biologically present in low concentrations from the plants remain preserved and yet are able to be used for the standardization of herbal products [21]. The phytochemical discovery from plant material can be achieved using an appropriate extraction process. Extraction is a process involving separating a mixture of compounds from non-miscible phases using a specific solvent. There are many factors influencing the quality (bioactivity) and quantity of the extract including types of solvents, techniques, and the parts of the plant used [22]. A proper extraction technique should be fully considered during extracting the bioactive constituents to assure that the target components are not lost, distorted, or destroyed. The emerging of modern extraction techniques by utilizing ultrasonic, supercritical fluid, microwave, and pressurized liquid proved to better extraction techniques with 
various advantages as compared to conventional methods (maceration, soxhlet, digestion, and reflux). For example, ultrasonic-assisted extraction (UAE) is easy to handle, has a faster extraction time, and consumes less energy [23].

C. papaya was commonly extracted by conventional techniques such as boiling [24,25] and shaking [26,27]. In this study, the ultrasonic, reflux, and agitation extraction techniques of C. papaya were analyzed for their effects on the secondary metabolites and phytochemicals profiling. Subsequently, the in vitro wound-healing capacity was examined using human skin fibroblasts.

\section{Results and Discussion}

\subsection{Percentage Yield and Secondary Metabolites Screening of C. papaya Extracts}

The yield of the C. papaya extracts is presented in Table 1. The result showed that the reflux technique produced the highest yield of $17.86 \%$ followed by agitation $(15.86 \%)$ and UAE $(13.57 \%)$. The dissimilar result of the yield might due to the different mode of action in which the reflux method uses heat to break down the cell wall of the plant, while UAE and agitation use ultrasonic wave and mechanical force, respectively. The heat applied on the extract facilitates the diffusion and solubility of the bioactive compounds, resulting in an increase of releasing of intracellular compounds. At any non-conventional method applied, the efficiency of the extraction rate is dependent on the choice of solvent [28]. Moreover, the result also was in an agreement with the results reported by Sultana et al., 2009 , who found that reflux produced the highest yield regardless of the plant material and solvent used [29].

Table 1. Extraction yield of C. papaya leaves obtained by different extraction techniques. UAE: ultrasonic-assisted extraction.

\begin{tabular}{cc}
\hline Extraction Techniques & Extraction Yields (\%) \\
\hline UAE & $13.57 \pm 0.18^{\mathrm{a}}$ \\
Reflux & $17.86 \pm 1.61^{\mathrm{b}}$ \\
Agitation & $15.86 \pm 0.91^{\mathrm{c}}$ \\
\hline
\end{tabular}

Values are presented as mean \pm standard deviation of three replicates. The different letter indicates there are significant differences $(p \leq 0.05)$.

Additionally, secondary metabolites screening showed the presence of saponins, flavonoids, coumarins, alkaloids, and phenolics in the leaves extracts of $C$. papaya by using all three extraction techniques (Table 2). However, terpenoids and steroids were not detected in the extracts. Various studies have shown that these compounds have a vast impact on wound-healing activities. For instance, saponin, which is known as ginsenoside from ginseng, has been proven to accelerate neovascularization in burn wound skin [30], while flavonoids also have been proven to increase the rate of wound contraction and hydroxyproline content, indicating an enhanced synthesis of collagen [31,32]. A triterpenoid saponin-rich fraction from Centella asiatica studied by Mahmood et al., 2016 can decrease Interleukin - $1 \beta$ (IL-1 $\beta$ ) and Nuclear factor kappa $\beta$ (NF-kB), and it augments tissue regeneration and excision wound repair [33].

\subsection{Antioxidant Activity by DPPH}

The antioxidant capacity of C. papaya leaves extracts was measured via DPPH radical scavenging inhibitory activity as illustrated in Figure 1 and Table 3 . The reflux technique produced the lowest $\mathrm{IC}_{50}$ $(0.236 \pm 0.009 \mathrm{mg} / \mathrm{mL})$ followed by UAE $(0.377 \pm 0.014 \mathrm{mg} / \mathrm{mL})$ and agitation $(0.404 \pm 0.009 \mathrm{mg} / \mathrm{mL})$. Meanwhile, the $\mathrm{IC}_{50}$ values of the positive controls were much lower than the C. papaya extracts with $0.014 \pm 0.002 \mathrm{mg} / \mathrm{mL}$ for ascorbic acid and $0.00625 \pm 0.001 \mathrm{mg} / \mathrm{mL}$ for quercetin. 
Table 2. Secondary metabolites of $C$. papaya leaves extract.

\begin{tabular}{cccc}
\hline Test & UAE & Reflux & Agitation \\
\hline Saponins & + & + & + \\
Flavonoids & + & + & + \\
Terpenoids & - & - & - \\
Steroids & - & - & - \\
Coumarins & + & + & + \\
Alkaloids & + & + & + \\
Phenolics & + & + & + \\
\hline
\end{tabular}

-: indicates Absence, +: indicates Presence.

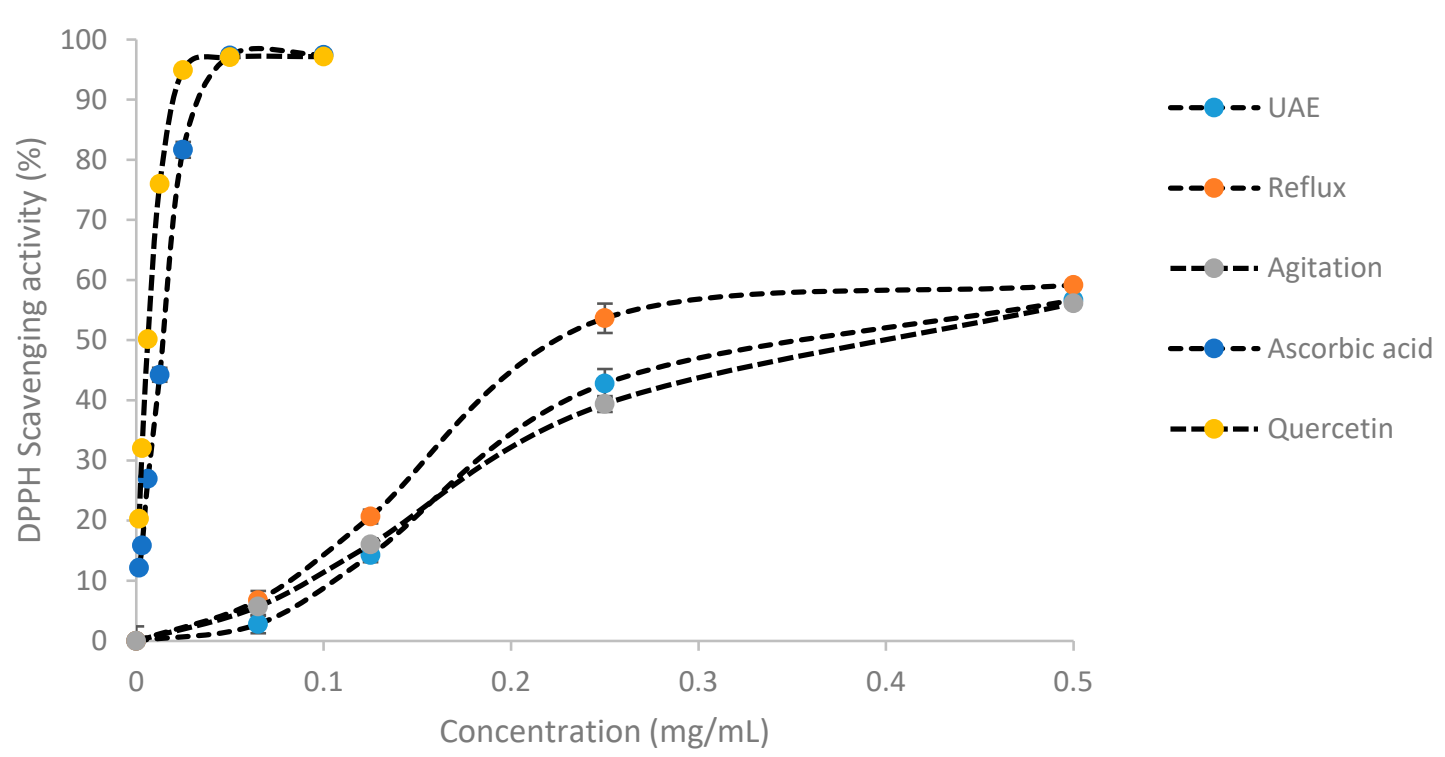

Figure 1. DPPH scavenging activity of UAE, reflux, and agitation C. papaya extracts. Results were expressed as the mean of three independent experiments.

Table 3. $\mathrm{IC}_{50}$ of 2, 2-diphenyl-1-picrylhydrazyl (DPPH) radical scavenging activity of C. papaya leaves extracts.

\begin{tabular}{cc}
\hline Sample & $\mathrm{IC}_{\mathbf{5 0}}(\mathrm{mg} / \mathrm{mL})$ \\
\hline Extracts & \\
\hline UAE & $0.377 \pm 0.014^{\mathrm{a}}$ \\
Reflux & $0.236 \pm 0.009^{\mathrm{b}}$ \\
Agitation & $0.404 \pm 0.009^{\mathrm{c}}$ \\
\hline Positive Control & \\
\hline Ascorbic acid & $0.014 \pm 0.002^{\mathrm{d}}$ \\
Quercetin & $0.00625 \pm 0.001^{\mathrm{e}}$ \\
\hline
\end{tabular}

Data represent the mean \pm SD of three independent experiments. The different letters indicate that there are significant differences $(p \leq 0.05)$.

\subsection{Wound-Healing Activities}

\subsubsection{Cytotoxicity and Proliferation Activities}

Basic cytotoxicity and cell proliferation tests were carried out using a sulforhodamine staining assay. In this study, for all the tested concentrations $(12.5 \mu \mathrm{g} / \mathrm{mL}$ to $500 \mu \mathrm{g} / \mathrm{mL})$, no cytotoxicity effects were observed for all the extracts, as shown in Figure 2. Interestingly, extracts produced from UAE (Figure 2A) and reflux (Figure 2B) significantly proliferated the cells' population. Moreover, 
reflux enhances the cells' number up to $85 \%$ higher than control, suggesting the suitability of C. papaya extracts for wound-healing agents.

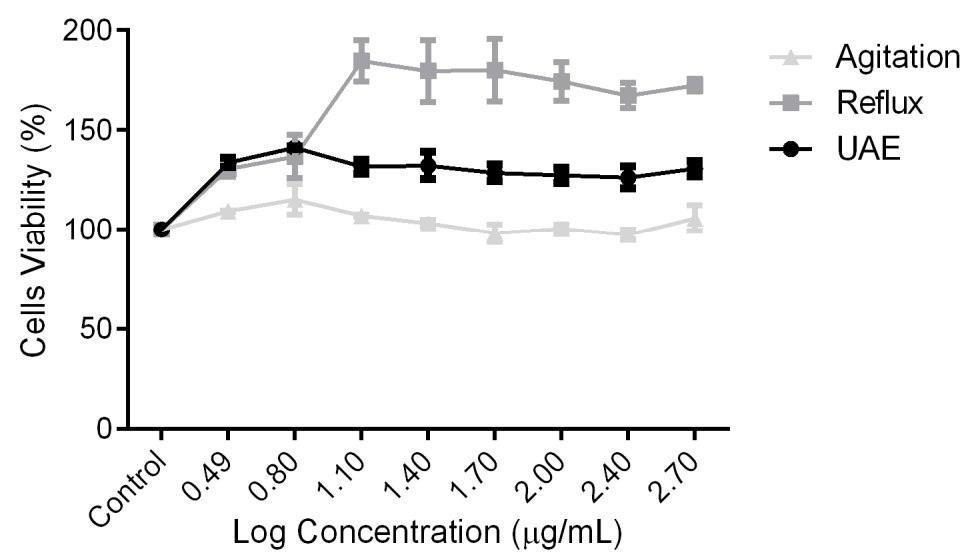

Figure 2. Cytotoxicity effect of C. papaya leaves extracts on the cell viability of HSF1184. (A) UAE, (B) reflux, $(\mathbf{C})$ agitation. Results are expressed as the mean of three independent experiments.

\subsubsection{Migration Effects of $C$. papaya Extract on HSF1184 Cell Lines}

To determine the effect of $C$. papaya extracts on the cells' migration and proliferation rate, the scratch areas on post-confluent HSF 1184 were treated for $48 \mathrm{~h}$ with non-toxic doses of extracts ranging from 12.5 to $100 \mu \mathrm{g} / \mathrm{mL}$. Figure 3 showed that in the early $24 \mathrm{~h}$ of treatment, the migration rate was faster at lower concentrations as compared to higher concentrations for all extracts. At $12.5 \mu \mathrm{g} / \mathrm{mL}$, as compared to control, the migration rate was $30 \%$ higher in reflux, followed by agitation $(27.5 \%)$ and UAE $(20.7 \%)$. Meanwhile, for other concentrations, no significant differences were measured in the early $24 \mathrm{~h}$ of treatment. Cell migration indicates the second phase of the wound-healing mechanism characterized by the migration of existing cells in the early $24 \mathrm{~h}$ post-wounded, followed by the proliferation of new cells on the wounded area [34].

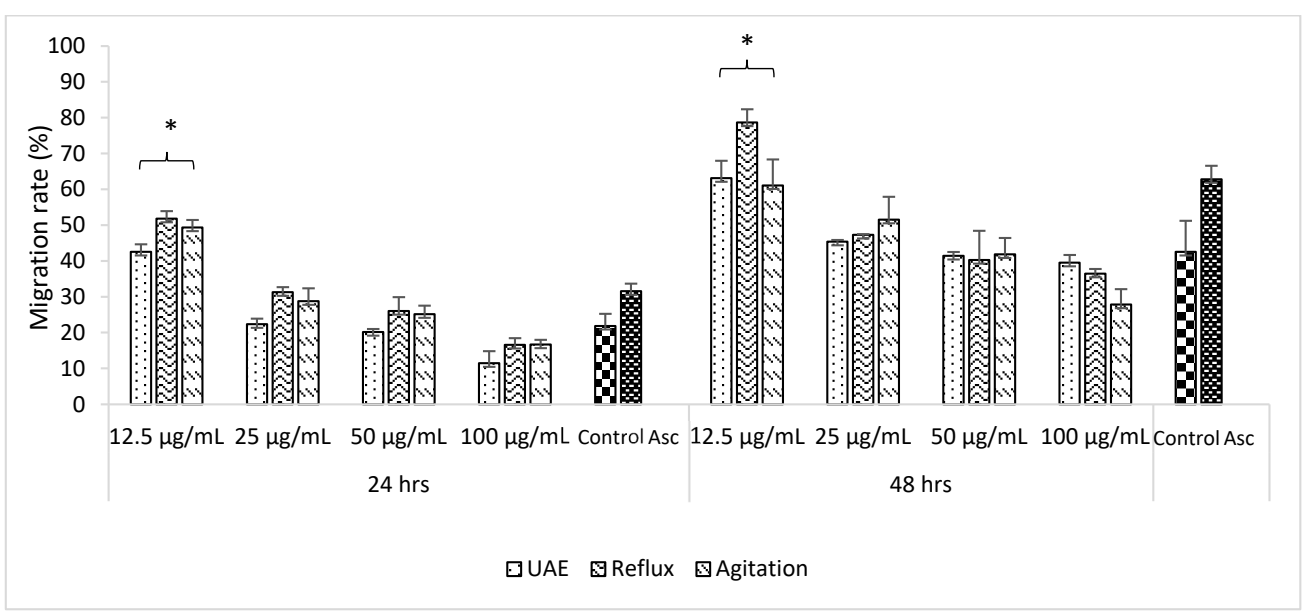

Figure 3. Effect of $C$. papaya extracts obtained from UAE, reflux, and agitation extraction techniques on the migration and proliferation rate of scratch HSF1184 cells. The migration rate was analyzed by using Image-J software. Results are expressed as the mean \pm SEM of three independent experiments.

At $48 \mathrm{~h}$ of treatment with $12.5 \mu \mathrm{g} / \mathrm{mL}$ of extracts, consistent with radical scavenging activity and cytotoxicity assay, the reflux technique possessed the highest proliferation rate $(78.67 \% \pm 4.85)$ followed by UAE $(63.12 \% \pm 3.69)$ and agitation $(61.09 \% \pm 7.27)$, respectively. The result was in agreement with other studies suggesting the pivotal role of antioxidants on wound recovery [35,36]. Excessive and prolonged reactive oxidant species during the inflammatory phase may damage the surrounding 
tissues and lead to the impairment of wound healing. Therefore, the choice of extraction technique may contribute to the conservation of these protective components associated with radical scavenging activity, hence stimulating the migration of cells toward the wound area. Representative images of the cell migration after $24 \mathrm{~h}$ and $48 \mathrm{~h}$ of treatment with extracts can be visualized in Figure 4.

Hour 0

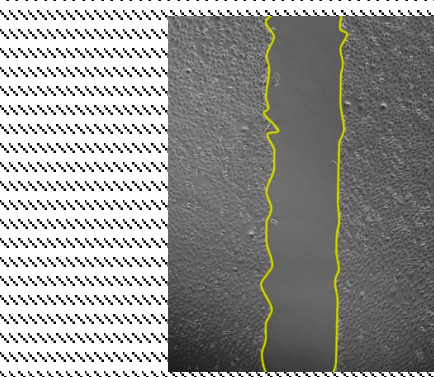

UAE

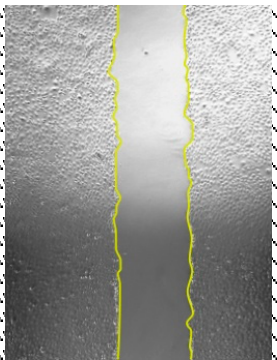

Reflux

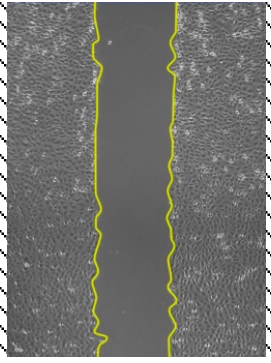

Agitation

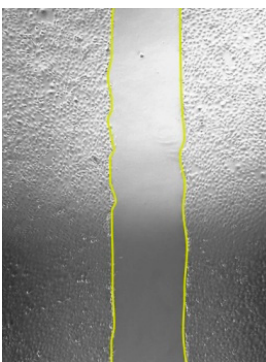

Positive

control

(Ascorbic

acid)
Hour 24
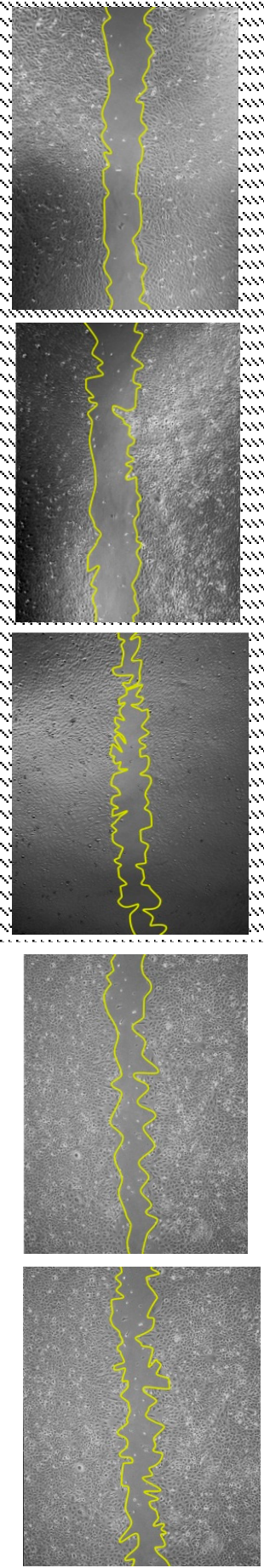

Hour 48
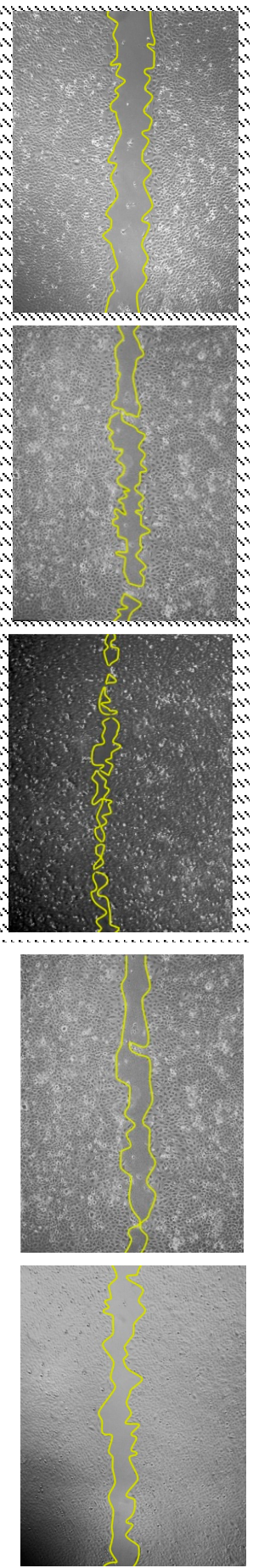

Figure 4. Images of the scratch area during the treatment of $12.5 \mu \mathrm{g} / \mathrm{mL}$ of extracts for $24 \mathrm{~h}$ and $48 \mathrm{~h}$. The migration rate cell was analyzed by Image-J software. 


\subsubsection{Collagen Synthesis by C. papaya Extracts}

During the wound-healing process, an abundance secretion of collagen is stimulated and released to accelerate epithelial regeneration. As shown in Table 4, at $24 \mathrm{~h}$ post-treatment, HSF1184 cells synthesized a significant $(p \leq 0.05)$ number of collagen except when cells were treated with the UAE extraction technique. However, at $48 \mathrm{~h}$ post-treatment, collagen production rapidly increased to a greater level than at $24 \mathrm{~h}$ treatment. Additionally, collagen synthesis was more pronounced in cells treated with extract obtained from the reflux method as compared to agitation and the UAE method. This result could be related to the type of solvent used during the extraction process. As previously discussed, at any non-conventional extraction method applied, the extraction competence depends on the choice of the solvent. [28]. Methanol extract from C. papaya was postulated to be the most efficient solvent as compared to water, ethanol, methanol, n-butanol, dichloromethane, ethyl acetate, and n-hexane for antioxidant and antibacterial effects [13], and it is believed that these effects could contribute to the activities of wound healing. Moreover, these provide rational as to why old practitioners apply heat to extract the plant benefit. Moreover, the concentration used during this study was selected based on the migration assay, by which a concentration of $12.5 \mu \mathrm{g} / \mathrm{mL}$ promotes the highest migration activity on HSF1184 cells. The quantitative analysis of collagen stimulated by extracts was quantified using a calibration equation $\left(\mathrm{y}=0.0136 \mathrm{x}-0.0223, R^{2}=0.9982\right)$.

Table 4. Effects of C. papaya extract treatment from various extraction techniques on collagen synthesis in HSF1184 cells after 24 and $48 \mathrm{~h}$ at a concentration of $12.5 \mu \mathrm{g} / \mathrm{mL}$.

\begin{tabular}{ccccc}
\hline Extracts & $\mathbf{2 4} \mathbf{h}$ & S.E.M & $\mathbf{4 8} \mathbf{h}$ & S.E.M \\
\hline UAE & 100.59 & 5.28 & $136.31 *$ & 0.39 \\
Reflux & $131.65 *$ & 5.86 & $164.89 *$ & 0.67 \\
Agitation & $119.93 *$ & 4.69 & $160.25 *$ & 5.22 \\
Control & 100 & - & 100 & - \\
\hline & $* p \leq 0.05$.
\end{tabular}

\subsection{Metabolite Profiling of C. papaya Extract from Reflux Technique}

The High Performance Liquid Chromatography Tandem Mass Spectrometry of Quadrupole Time-of-Flight (HPLC-MS QTOF) analysis of C. papaya from the reflux technique revealed a considerable amount of nine phytochemical compounds, including alkaloids and flavonoids (Table 5). HPLC chromatogram of these phytochemicals were illustrated in supplementary material (Figure S1). Data obtained from this analysis were in agreement with most reports describing that the most abundant compounds extracted from C. papaya were polar compounds [5,13]. A study has successfully isolated seven flavonoids from the butanol fraction of methanol extract from C. papaya leaves consisting of quercetin 3-( $2^{\mathrm{G}}$-rhamnosyrutinoside), kaempherol 3-( $2^{\mathrm{G}}$-rhamnosylrutinoside), quercetin 3-rutinoside, myricetin 3-rhamnoside, kaempherol 3-rutinoside, quercetin, and kaempherol, which have been tested on antioxidant activity by peroxynitrite scavenging assays [14]. In addition, methanol was found to extract many compounds rather than other solvents [37]. Flavonoids are well known for secondary metabolites that show a good significant contribution against wound-healing activities [38,39]. Kaempherol and luteolin are classified under flavonoid compounds that have been proved to exert wound-healing activities on diabetic and non-diabetic rats [38-40]. In the C. papaya plant, carpaine is a major alkaloid compound. It has been evaluated to exert antithrombocytopenic effects [19]. All these compounds supported that the synergistic effect of these phytochemical compounds present in the C. papaya leaves extract contributed to the bioactivities of $C$. papaya. 
Table 5. Mass spectral analysis of the compounds present in the extract of $C$. papaya leaves using the reflux method.

\begin{tabular}{llllrr}
\hline No. & \multicolumn{1}{c}{$\boldsymbol{t}_{\mathbf{R}}(\mathbf{m i n})$} & \multicolumn{1}{c}{ Compound } & Mass & Difference $(\mathbf{p p m})$ & \multicolumn{1}{c}{ Score } \\
\hline 1. & 1.64 & Carpaine & 478.379 & -3.66 & 98.48 \\
2. & 1.807 & Kaempferol 3-(2G-glucosylrutinoside) & 756.2128 & -1.97 & 96.85 \\
3. & 2.069 & Kaempferol 3-(2"-rhamnosylgalactoside) 7-rhamnoside & 740.2185 & -2.88 & 97.22 \\
4. & 2.14 & Kaempferol 3-rhamnosyl-(1->2)-galactoside-7-rhamnoside & 740.2187 & -3.07 & 96.85 \\
5. & 2.447 & Luteolin 7-galactosyl-(1->6)-galactoside & 610.1560 & -4.35 & 97.55 \\
6. & 2.951 & Orientin 7-O-rhamnoside & 594.1606 & -3.67 & 98.19 \\
7. & 4.913 & 11-hydroperoxy-12,13-epoxy-9-octadecenoic acid & 328.2263 & -3.99 & 98.95 \\
8. & 5.386 & Palmitic amide & 255.257 & -4.18 & 94.74 \\
9. & 6.632 & 2-Hexaprenyl-6-methoxyphenol & 532.428 & -0.31 & 98.13 \\
\hline
\end{tabular}

$t_{\mathrm{R}}$, retention time.

\section{Materials and Methods}

\subsection{Materials}

2, 2-diphenyl-1-picrylhydrazyl (DPPH), thiazolyl blue tetrazolium bromide (MTT), and ascorbic acid were purchased from Sigma-Aldrich ${ }^{\circledR}$ (St. Louis, MO, USA). HPLC-grade methanol, formic acid, ethanol, acetonitrile, and Folin-Ciocalteu reagent were purchased from Merck ${ }^{\circledR}$ (Darmstadt, Germany). Penicillin streptomycin, Dulbecco's modified eagle medium (DMEM), trypsin Ethylenediaminetetraacetic acid (EDTA), phosphate-buffered saline (PBS), and fetal bovine serum (FBS) were obtained from GIBCO $^{\circledR}$ (Carlsbad, CA, USA). Insoluble collagen assay-Sircol ${ }^{\mathrm{TM}}$ was purchased from Biocolor (Carrickfergus, UK).

\subsection{Plant Material Collection}

The green leaves of C. papaya cultivar "Eksotika" were collected from the Malaysian Agriculture Research and Development Institute (MARDI) (Serdang, Selangor, Malaysia). The sample was authenticated by botanist Dr. Shamsul Khamis, and a voucher specimen (SK 3143/17) was deposited at the Herbarium Institute of Bioscience, Universiti Putra Malaysia, Serdang, Selangor, Malaysia. Leaves were washed with tap water and dried in an oven at $50^{\circ} \mathrm{C}$ for 2 days and then blended to obtain a fine powder using a Waring blender.

\subsection{Extraction}

\subsubsection{Ultrasonic-Assisted Extraction (UAE)}

UAE was performed using a Fisherbrand ${ }^{\mathrm{TM}} \mathrm{Q} 125$ probe sonicator instrument. C. papaya powder $(7.5 \mathrm{~g})$ were extracted in $100 \mathrm{~mL}$ of methanol for $20 \mathrm{~min}$ at a frequency of $60 \mathrm{~Hz}$. The extract was filtered using Whatman No. 1 filter paper and evaporated to dryness. The dried extracts were stored at $-20^{\circ} \mathrm{C}$ until further use.

\subsubsection{Reflux}

Reflux extraction was carried out by heating $7.5 \mathrm{~g}$ of round leaves of C. papaya in $100 \mathrm{~mL}$ of methanol for $20 \mathrm{~min}$. The extract was filtered using Whatman No. 1 filter paper and evaporated to dryness. The dried extract was stored at $-20^{\circ} \mathrm{C}$ until further use.

\subsection{Agitation}

The agitation method was carried out using an incubation shaker (Sartorius Certomat ${ }^{\circledR}$ SII, Goettingen, Germany). A similar amount of C. papaya powder was extracted in $100 \mathrm{~mL}$ of methanol. The extract was agitated at $200 \mathrm{rpm}$ for $20 \mathrm{~min}$ at room temperature. The extract was filtered using Whatman No. 1 filter paper and evaporated to dryness. The dried extract was stored at $-20^{\circ} \mathrm{C}$ until further use. 


\subsection{Recovery Yield}

The yield of $C$. papaya extract obtained from all extraction techniques was calculated based on Equation (1).

$$
\text { Recovery Yield }(\%)=\frac{W_{1}}{W_{0}} \times 100
$$

where $W_{1}$ is the weight of sample after drying, and $W_{0}$ is the weight of dried leaves powder before drying.

\subsection{Qualitative Secondary Metabolites Analysis}

Extracts were subjected to qualitative secondary metabolites screening to identify the presence of saponins, flavonoids, terpenoids, steroids, coumarins, alkaloids, phenolics, and tannins. The analysis was carried out as described by Trease and Evans [41].

\subsection{Test for Saponins}

One $\mathrm{mL}$ of leaves extract was diluted with $3 \mathrm{~mL}$ of distilled water. Then, it was shaken for $15 \mathrm{~min}$. The formation of a $1 \mathrm{~cm}$ layer of foam indicates the presence of saponin.

\subsection{Test for Flavonoids}

One $\mathrm{mL}$ of leaves extract was diluted with $1 \mathrm{~mL}$ of sodium hydroxide and hydrochloric acid. The development of yellow solution indicates the presence of flavonoids.

\subsection{Test for Terpenoids}

One $\mathrm{mL}$ of leaves extract was mixed with $2 \mathrm{~mL}$ of chloroform and $2 \mathrm{~mL}$ of concentrated sulfuric acid. The formation of a reddish-brown color at the interface indicates the presence of terpenoids.

\subsection{Test for Steroids}

One $\mathrm{mL}$ of leaves extract was mixed with $10 \mathrm{~mL}$ of chloroform followed by the addition of $10 \mathrm{~mL}$ of concentrated sulfuric acid. The formation of a red color on the upper layer indicates the presence of steroids while the addition of sulfuric acid showed yellow with green fluorescence.

\subsection{Test for Coumarins}

One $\mathrm{mL}$ of leaves extract was mixed with $1 \mathrm{~mL}$ of sodium hydroxide $(10 \%)$. The yellow color indicates the presence of coumarins.

\subsection{Test for Alkaloids}

An equal volume of extracts was mixed with concentrated hydrochloric acid. Then, a few drops of Mayer's reagent were added into a mixture. The presence of a green color or white precipitate indicates the presence of alkaloids.

\subsection{Test for Phenolics and Tannins}

One $\mathrm{mL}$ of leaves extract was mixed with $2 \mathrm{~mL}$ of distilled water followed by a few drops of ferric chloride (10\%). A blue or green color indicates the presence of phenols.

\subsection{Determination of 1,1-diphenyl-2-picrylhydrazy (DPPH) Scavenging Activity}

The scavenging activity of extracts against DPPH radical was assessed based on the method suggested by Maisarah et al., with some modifications [42]. Prior to reaction, extracts were diluted in methanol to produce a series of concentrations from 0.065 to $0.5 \mathrm{mg} / \mathrm{mL}$. Then, DPPH solution $(0.2 \mathrm{mM})(100 \mu \mathrm{L})$ was added into each well plate containing different concentrations of the extracts. 
The mixture was kept in the dark at room temperature for $30 \mathrm{~min}$. Ascorbic acid and quercetin were used as reference standards. The absorbance was measured at $517 \mathrm{~nm}$, whereas the activity of radical scavenging was calculated using Equation (2). The values of inhibitory concentration $\left(\mathrm{IC}_{50}\right)$ were determined using Graphpad Prism 5 software.

$$
\text { DPPH scavenging activity }(\%)=\frac{\left(A_{0}-A_{1}\right)}{A_{0}} \times 100
$$

where $A_{0}$ is the absorbance of the control and $A_{1}$ is the absorbance of the extract or standard.

\subsection{Cell Culture and Maintenance}

Human skin fibroblast (HSF1184) cells (ECACC, United Kingdom) were maintained in DMEM, supplemented with 10\% FBS and 1\% Penicillin Streptomycin (PS), and incubated under 5\% $\mathrm{CO}_{2}$ at 37 ${ }^{\circ} \mathrm{C}$. Prior to the in vitro analysis, the extracts were prepared by dissolving in the cell culture media (without serum) and diluted to a respective concentration applied.

\subsection{Cytotoxicity Assay via Sulforhodamine B (SRB) Assay}

Cytotoxicity assay on HSF1184 was conducted according to Vinchai and Kirtikara, with modifications [43]. Briefly, 15,000 cells were seeded in 96-well culture plates and incubated overnight. Cells were treated with extracts $(12.5 \mu \mathrm{g} / \mathrm{mL}$ to $500 \mu \mathrm{g} / \mathrm{mL})$ for $24 \mathrm{~h}$. Cells' viability was assayed by SRB. Color development was measured at $510 \mathrm{~nm}$.

\subsection{Scratch Assay}

A scratch assay was carried out according to Ahmad et al., with minor modifications [44]. Briefly, 300,000 cells were seeded into six-well plates and allowed to reach confluency for $48 \mathrm{~h}$. A linear scratch was made using a sterile fine tip and rinsed with PBS to remove cell debris. Subsequently, $3 \mathrm{~mL}$ of the extracts ranging from $12.5 \mu \mathrm{g} / \mathrm{mL}$ to $100 \mu \mathrm{g} / \mathrm{mL}$ was added into each well. Ascorbic acid (5 ug/mL) was served as positive control, while cell culture media without serum served as the negative control. The closure of the scratch area was recorded after $48 \mathrm{~h}$ of treatment using an inverted microscope equipped with a digital camera. The image was analyzed using image analysis software, Image J. The percentage of closure was calculated using Equation (3).

$$
\text { Migration rate }(\%)=\frac{\text { Area } t: 0-\text { Area } t: 48}{\text { Area } t: 0} \times 100
$$

where $t: 0$ is the average scratch area at ' 0 ' time, and $t: 48$ is the average scratch area after $48 \mathrm{~h}$ of treatment.

\subsection{Collagen Synthesis Assay}

Collagen syntheses by cells were measured using Sircol collagen assay (Biocolor Ltd, Carrickfergus, UK). Pre-confluent cells were treated with $12.5 \mu \mathrm{g} / \mathrm{mL}$ of extracts for $48 \mathrm{~h}$. Spent media was collected and mixed with $200 \mu \mathrm{L}$ of isolation and concentration reagent. The mixture was incubated overnight at $4{ }^{\circ} \mathrm{C}$. One $\mathrm{mL}$ of Sircol dye reagent was added and mixed vigorously for $5 \mathrm{~min}$. Then, the mixture was centrifuged at 12,000 rpm for $10 \mathrm{~min}$, and the supernatant was removed prior to the addition of $750 \mu \mathrm{L}$ ice-cold acid-salt wash reagent. After centrifugation and removal of the supernatant, an alkali reagent was added into the tube and the mixture was measured at $555 \mathrm{~nm}$.

\subsection{HPLC-MS/MS-QTOF Analysis}

Metabolite profiling analysis was performed on an Agilent 6560 Ion Mobility connected to a Quadrupole Time-of-Flight (IM-QTOF) HPLC/MS system equipped with a dual electroscopy ionization (ESI) source (Agilent Technologies, Santa Clara, CA, USA). Chromatographic separation was achieved 
on a Zorbax Eclipse plus C18 column $(2.1 \mathrm{~mm} \times 50 \mathrm{~mm}, 1.8 \mu \mathrm{m})$ (Agilent Technologies, Santa Clara, CA, USA) operated at $25^{\circ} \mathrm{C}$ employing a gradient elution using $0.1 \%$ formic acid in water [A] and $0.1 \%$ formic acid in methanol [B] as the mobile phase at a flow rate of $0.3 \mathrm{~mL} / \mathrm{min}$. The following gradient elution was adopted: $35-90 \%$ B for the first 0 to $7 \mathrm{~min} ; 90-90 \%$ B for 7 to $25 \mathrm{~min} ; 90-35 \%$ B for 25 to $35 \mathrm{~min}$; the initial condition was maintained for $5 \mathrm{~min}$. The sample injection volume was $3 \mu \mathrm{L}$.

The mass spectrometer was operated in both positive and negative electrospray ionization modes. The mass spectra were recorded by scanning the mass range from $m / z 100$ to 3000 in both MS and MS/MS modes. The gas temperature was set to $200{ }^{\circ} \mathrm{C}$, and the drying gas flow rate was $12 \mathrm{~L} / \mathrm{min}$. The nebulizer pressure was $20 \mathrm{psi}$, the sheath gas temperature was $400^{\circ} \mathrm{C}$, and the sheath gas flow was $12 \mathrm{~L} / \mathrm{min}$. The source parameters such as capillary voltage was $2500 \mathrm{~V}$, whilst the nozzle voltage was $500 \mathrm{~V}$.

Data analysis was performed using Agilent MassHunter Qualitative software, Version B.06.00 (Agilent Technologies, Santa Clara, CA, USA) with Molecular Feature Extractor (MFE) algorithms in concert with Mass Profiler Professional software, Version 12.1 (Agilent Technologies, Santa Clara, CA, USA). The compound identification was carried out by using a Personal Compound Database Library (PCDL) (Agilent, Santa Clara, CA, USA) with the METLIN Personal Metabolite Database and a customized PCDL database (peptides, metabolites, lipids, AMRT, and AM).

\subsection{Statistical Analysis}

All data were analyzed by using one-way ANOVA, SPSS Version 17.0 (IBM corporation, New York, U.S.A). The significance of the results was determined by Tukey's test, and a $p$ value of 0.05 was set as the limit of significant difference. The results were expressed as mean \pm standard deviation (STDEV) or standard error mean (SEM).

\section{Conclusions}

Our finding concluded that the extraction of C. papaya was optimum using the reflux technique, which produced the highest antioxidant activity, promoted cells proliferation and migration, and was an excellent promoter for collagen synthesis as well. Further studies should explore the optimum conditions of the reflux process for the wound-healing properties of methanolic extracts of $C$. papaya.

Supplementary Materials: The following are available online at http://www.mdpi.com/1420-3049/25/3/517/s1, Figure S1: Compounds profiles of $C$. papaya obtained from reflux technique.

Author Contributions: H.H.S., H.Y. and M.R.S. designed the research; H.H.S., H.F.I. and F.H. performed the experimental work (supervised by H.Y. and M.R.S.); H.H.S wrote the original manuscript; M.H.A.B., M.F.I., F.H. and H.H.S revised the manuscript. All authors have read and agree to the published version of the manuscript.

Funding: This work was supported by the Ministry of Education and Universiti Teknologi Malaysia for the grant scheme under High Center of Excellence [Vote number: R.J130000.7846.4J261].

Conflicts of Interest: The authors declare no conflict of interests.

\section{References}

1. Gadgoli, C. Research in Phyto-Constituents for Treatment of Wounds; IntechOpen: London, UK, 2016.

2. Juárez-Rojop, I.E.; Tovilla-Zárate, C.A.; Aguilar-Domínguez, D.E.; Fuente, L.F.R.-d.l.; Lobato-García, C.E.; Blé-Castillo, J.L.; López-Meraz, L.; Díaz-Zagoya, J.C.; Bermúdez-Ocaña, D.Y. Phytochemical screening and hypoglycemic activity of Carica papaya leaf in streptozotocin-induced diabetic rats. Revista Brasileira de Farmacognosia 2014, 24, 341-347.

3. Nwaehujor, C.O.; Ode, J.O.; Ekwere, M.R.; Udegbunam, R.I. Anti-fertility effects of fractions from Carica papaya (Pawpaw) Linn. Methanol root extract in male Wistar rats. Arab. J. Chem. 2019, 12, 1563-1568. [CrossRef]

4. Chavez-Quintal, P.; Gonzalez-Flores, T.; Rodriguez-Buenfil, I.; Gallegos-Tintore, S. Antifungal Activity in Ethanolic Extracts of Carica papaya L. cv. Maradol Leaves and Seeds. Indian J. Microbiol. 2011, 51, 54-60. [CrossRef] 
5. Tay, Z.; Chong, K. The potential of papaya leaf extract in controlling ganoderma boninense. In Proceedings of the IOP Conference Series: Earth and Environmental Science, Sabah, Malaysia, 9-12 December 2015; Volume 36, p. 012027.

6. Kumarasamy, S.; Deepa, P.; Harisaranraj, R.; Achudhan, V. Antimicrobial and Phytochemical Investigation of the Leaves of Carica papaya L., Cynodon dactylon (L.) Pers., Euphorbia hirta L., Melia azedarach L. and Psidium guajava L. Ethnobot. Leafl. 2008, 12, 1184-1191.

7. Baskaran, C.; Velu, S.; Kumaran, K. The efficacy of carica papaya leaf extract on some bacterial and a fungal strain by well diffusion method. Asian Pac. J. Trop. Dis. 2012, 2, S658-S662. [CrossRef]

8. Zuhrotun Nisa, F.; Astuti, M.; Murdiati, A.; Mubarika Haryana, S. Anti-proliferation and apoptosis induction of aqueous leaf extract of carica papaya 1. on human breast cancer cells mcf-7. Pak. J. Biol. Sci. 2017, 20, 36-41. [CrossRef] [PubMed]

9. Imaga, N.; Gbenle, G.; Okochi, V.; Adenekan, S.; Duro-Emmanuel, T.; Oyeniyi, B.; Dokai, P.; Oyenuga, M.; Otumara, A.; Ekeh, F. Phytochemical and antioxidant nutrient constituents of Carica papaya and Parquetina nigrescens extracts. Sci. Res. Essays 2010, 5, 2201-2205.

10. Kala, C.P. Leaf juice of Carica papaya L.: A remedy of dengue fever. Med. Aromat. Plants 2012, 1, 109.

11. Melariri, P.; Campbell, W.; Etusim, P.; Smith, P. Antiplasmodial Properties and Bioassay-Guided Fractionation of Ethyl Acetate Extracts from Carica papaya Leaves. J. Parasitol. Res. 2011, 2011, 104954. [CrossRef] [PubMed]

12. Abdullah Sani, M.S.; Bakar, J.; Abdul Rahman, R.; Abas, F. The antibacterial activities and chemical composition of extracts from Carica papaya cv. Sekaki/Hong Kong seed. Int. Food Res. J. 2017, $24,810$.

13. Asghar, N.; Naqvi, S.A.; Hussain, Z.; Rasool, N.; Khan, Z.A.; Shahzad, S.A.; Sherazi, T.A.; Janjua, M.R.; Nagra, S.A.; Zia-Ul-Haq, M.; et al. Compositional difference in antioxidant and antibacterial activity of all parts of the Carica papaya using different solvents. Chem. Cent. J. 2016, 10, 5. [CrossRef] [PubMed]

14. Nugroho, A.; Heryani, H.; Choi, J.S.; Park, H.-J. Identification and quantification of flavonoids in Carica papaya leaf and peroxynitrite-scavenging activity. Asian Pac. J. Trop. Biomed. 2017, 7, 208-213. [CrossRef]

15. Afzan, A.; Abdullah, N.R.; Halim, S.Z.; Rashid, B.A.; Semail, R.H.; Abdullah, N.; Jantan, I.; Muhammad, H.; Ismail, Z. Repeated dose 28-days oral toxicity study of Carica papaya L. leaf extract in Sprague Dawley rats. Molecules 2012, 17, 4326-4342. [CrossRef] [PubMed]

16. Tiwari, P.; Kumar, K.; Panik, R.; Pandey, A.; Pandey, A.; Sahu, P. Evaluation of aqueous extract of Roots of Carica papaya on wound healing activity in albino Rats. J. Chem. Pharm. Res. 2011, 3, 291-295.

17. Nafiu, A.B.; Rahman, M.T. Selenium added unripe carica papaya pulp extracts enhance wound repair through TGF-beta1 and VEGF-a signalling pathway. BMC Complement. Altern. Med. 2015, 15, 369. [CrossRef] [PubMed]

18. Abdulrazaq, N.; Abdulaziz, E.; Rahman, M. Carica papaya juice enhanced in-vitro cell proliferation better than freeze-dried PBS extract using scratch assay 11 2. Trop. J. Health Sci. 2016, 23, 18-22.

19. Zunjar, V.; Dash, R.P.; Jivrajani, M.; Trivedi, B.; Nivsarkar, M. Antithrombocytopenic activity of carpaine and alkaloidal extract of Carica papaya Linn. Leaves in busulfan induced thrombocytopenic Wistar rats. J. Ethnopharmacol. 2016, 181, 20-25. [CrossRef]

20. Ghosh, P.K.; Gaba, A. Phyto-extracts in wound healing. J. Pharm. Pharm. Sci. 2013, 16, 760-820. [CrossRef]

21. Pandey, M.R.; Guo, H. Evaluation of cytotoxicity, genotoxicity and embryotoxicity of insecticide propoxur using flounder gill (FG) cells and zebrafish embryos. Toxicol. In Vitro 2014, 28, 340-353. [CrossRef]

22. Ncube, N.S.; Afolayan, A.J.; Okoh, A.I. Assessment techniques of antimicrobial properties of natural compounds of plant origin: Current Methods and Future Trends. Afr. J. Biotechnol. 2008, 7, 1797-1806. [CrossRef]

23. Medina-Torres, N.; Ayora, T.; Andrews, H.; Sanchez, A.; Pacheco López, N. Ultrasound assisted extraction for the recovery of phenolic compounds from vegetable sources. Agronomy 2017, 7, 47. [CrossRef]

24. Ancheta, M.; Acero, L. Wound healing property of Carica papaya stem in albino rats. Int. J. Biosci. Biochem. Bioinform. 2016, 6, 68-74. [CrossRef]

25. Nayak, S.B.; Pinto Pereira, L.; Maharaj, D. Wound healing activity of Carica papaya L. in experimentally induced diabetic rats. Indian J. Exp. Biol. 2007, 45, 739-743. [PubMed]

26. Anuar, N.S.; Zahari, S.S.; Taib, I.A.; Rahman, M.T. Effect of green and ripe Carica papaya epicarp extracts on wound healing and during pregnancy. Food Chem. Toxicol. 2008, 46, 2384-2389. [CrossRef] [PubMed]

27. Saeed, N.; Khan, M.R.; Shabbir, M. Antioxidant activity, total phenolic and total flavonoid contents of whole plant extracts Torilis leptophylla L. BMC Complement. Altern. Med. 2012, 12, 221. [CrossRef] [PubMed] 
28. Selvamuthukumaran, M.; Shi, J. Recent advances in extraction of antioxidants from plant by-products processing industries. Food Qual. Saf. 2017, 1, 61-81. [CrossRef]

29. Sultana, B.; Anwar, F.; Ashraf, M. Effect of extraction solvent/technique on the antioxidant activity of selected medicinal plant extracts. Molecules 2009, 14, 2167-2180. [CrossRef]

30. Kim, Y.S.; Cho, I.-H.; Jeong, M.-J.; Jeong, S.-J.; Nah, S.Y.; Cho, Y.-S.; Kim, S.H.; Go, A.; Kim, S.E.; Kang, S.S.; et al. Therapeutic effect of total ginseng saponin on skin wound healing. J. Ginseng Res. 2011, 35, 360-367. [CrossRef]

31. Geethalakshmi, R.; Sakravarthi, C.; Kritika, T.; Arul Kirubakaran, M.; Sarada, D.V.L. Evaluation of antioxidant and wound healing potentials of Sphaeranthus amaranthoides Burm. F. BioMed Res. Int. 2013, 2013, 607109. [CrossRef]

32. Dwivedi, D.; Dwivedi, M.; Malviya, S.; Singh, V. Evaluation of wound healing, anti-microbial and antioxidant potential of Pongamia pinnata in wistar rats. J. Tradit. Complement. Med. 2017, 7, 79-85. [CrossRef]

33. Mahmood, A.; Tiwari, A.; Sahin, K.; KÜÇÜK, Ö.; Ali, S. Triterpenoid saponin-rich fraction of Centella asiatica decreases IL-1 $\beta$ and NF- $\mathrm{kB}$, and augments tissue regeneration and excision wound repair. Turk. J. Biol. 2016, 40, 399-409. [CrossRef]

34. Syarina, P.N.A.; Karthivashan, G.; Abas, F.; Arulselvan, P.; Fakurazi, S. Wound healing potential of Spirulina platensis extracts on human dermal fibroblast cells. EXCLI J. 2015, 14, 385-393. [PubMed]

35. Kurahashi, T.; Fujii, J. Roles of Antioxidative Enzymes in Wound Healing. J. Dev. Biol. 2015, 3, 57-70. [CrossRef]

36. Cano Sanchez, M.; Lancel, S.; Boulanger, E.; Neviere, R. Targeting oxidative stress and mitochondrial dysfunction in the treatment of impaired wound healing: A systematic review. Antioxidants 2018, 7, 98. [CrossRef] [PubMed]

37. Cowan, M.M. Plant products as antimicrobial agents. Clin. Microbiol. Rev. 1999, 12, 564-582. [CrossRef] [PubMed]

38. Lodhi, S.; Singhai, A.K. Wound healing effect of flavonoid rich fraction and luteolin isolated from Martynia annua Linn. on streptozotocin induced diabetic rats. Asian Pac. J. Trop. Med. 2013, 6, 253-259. [CrossRef]

39. Özay, Y.; Güzel, S.; Yumrutaş, Ö.; Pehlivanoğlu, B.; Erdoğdu, İ.H.; Yildirim, Z.; Türk, B.A.; Darcan, S. Wound healing effect of kaempferol in diabetic and nondiabetic rats. J. Surg. Res. 2019, 233, 284-296. [CrossRef]

40. Bayrami, Z.; Khalighi-Sigaroodi, F.; Rahimi, R.; Farzaei, M.H.; Hodjat, M.; Baeeri, M.; Rahimifard, M.; Navaei-Nigjeh, M.; Abdollahi, M.; Hajiaghaee, R. In vitro wound healing activity of luteolin. Res. J. Pharmacogn. 2017, 4, 7.

41. Trease, G.E.; Evans, W.C. Pharmacognsy; Brailliar Tiridel Can Macmillian Publishers: London, UK, 1989.

42. Mutalib, M.; Amira, B.; Asmah, R.; Othman, F. Antioxidant analysis of different parts of Carica papaya. Int. Food Res. J. 2013, 20, 1043-1048.

43. Vichai, V.; Kirtikara, K. Sulforhodamine B colorimetric assay for cytotoxicity screening. Nat. Protoc. 2006, 1, 1112-1116. [CrossRef]

44. Ahmad, Z.; Sarmidi, M.R.; Hasham, R. Evaluation of wound closure activity of cocos nucifera oil on scratched monolayer of human dermal fibroblasts. Chem. Eng. Trans. 2017, 56, 1657-1662.

Sample Availability: Samples of the compounds (3) are available from the authors.

(C) 2020 by the authors. Licensee MDPI, Basel, Switzerland. This article is an open access article distributed under the terms and conditions of the Creative Commons Attribution (CC BY) license (http://creativecommons.org/licenses/by/4.0/). 